\title{
COMUNICAÇÃO
}

\section{AVALIAÇÃO DA CAPACIDADE DE PRODUZIR FITOTOXINAS IN VITRO POR PARTE DE FUNGOS COM PROPRIEDADES ANTAGÔNICAS A NEMATÓIDES}

\author{
In vitro evaluation of the phytotoxin production ability by fungi with \\ antagonic properties to nematodes
}

\author{
Daniel Diego Costa Carvalho ${ }^{1}$, Denilson Ferreira de Oliveira ${ }^{2}$, Vicente Paulo Campos ${ }^{3}$, \\ Moacir Pasqual ${ }^{4}$, Renato Mendes Gimarães ${ }^{5}$, Rogério Sebastião Batista Corrêa ${ }^{6}$
}

\begin{abstract}
RESUMO
Em trabalho preliminar foram obtidos 24 isolados fúngicos com propriedades antagônicas a nematóides parasitas de plantas segundo experimentos realizados em laboratório. Para dar continuidade a tal trabalho, tornou-se desejável dispor de metodologia simples e de baixo custo para selecionar aqueles sem capacidade de produção de substâncias fitotóxicas, para serem empregados em experimentos em casa-de-vegetação com fitonematóides. Conseqüentemente, cultivaram-se os fungos em meio líquido e, após filtração, as fases líquidas foram liofilizadas e extraídas com acetato de etila/metanol. Os extratos foram concentrados sob vácuo e dissolvidos em água e solução de sacarose para serem submetidos a testes in vitro com sementes de alface (Lactuca sativa L.) e com coleóptilos de trigo (Triticum aestivum L.), respectivamente. Vinte e três isolados pertencentes aos gêneros Arthrobotrys, Aspergillus, Coniothyrium, Cunninghamella, Cylindrocarpon, Fusarium, Monacrosporium, Mortierella, Paecilomyces, Penicillium, Sclerotinia, Trichoderma e Verticillium, apresentaram atividade tóxica contra os coleóptilos de trigo. Apenas os isolados de Cylindrocarpon magnusianum (Sacc.) Wollenw., Fusarium moniliforme Shelden, Mortierella sp., Paecilomyces lilacinus (Thom.) Samson e Penicillium sp. apresentaram atividade fitotóxica no teste com sementes de alface. Somente um isolado de $F$. moniliforme se mostrou inativo em ambos os testes, o que sugere que não seja produtor de fitotoxinas.
\end{abstract}

Termos para indexação: Antagonistas, controle biológico, fungos nematófagos, nematóide.

\begin{abstract}
In a previous work 24 fungi cultures were selected due to their antagonic properties to phytonematodes in laboratory experiments. To proceed to further studies, it became desirable to use a simple and inexpensive methodology to identify those fungi able to produce phytotoxic substances, so that only the non phytotoxin producers could be used in green-house experiments with plant parasite nematodes. Thus, fungi were grown in liquid medium and the resulting mixtures were submitted to filtration. The liquid phases were freeze-dried and extracted with ethyl acetate/methanol. After extracts concentration under vacuum, the remaining substances were dissolved in water and aqueous saccharose solution to be submitted to in vitro assays with lettuce seeds (Lactuca sativa L.) and wheat coleoptile (Triticum aestivum L.), respectively. Twenty three isolates from genera Arthrobotrys, Aspergillus, Coniothyrium, Cunninghamella, Cylindrocarpon, Fusarium, Monacrosporium, Mortierella, Paecilomyces, Penicillium, Sclerotinia, Trichoderma and Verticillium, presented toxic activity against wheat coleoptile, though only isolates of Cylindrocarpon magnusianum (Sacc.) Wollenw., Fusarium moniliforme Shelden, Mortierella sp., Paecilomyces lilacinus (Thom.) Samson and Penicillium sp., presented phytotoxic effects in the lettuce seeds assay. Only one isolate of $F$. moniliforme was inactive in both assays, what suggests that this fungus is not able to produce phytotoxins.
\end{abstract}

Index terms: Antagonists, biological control, nematophagous fungi, nematode.

(Recebido para publicação em 5 de agosto de 2004 e aprovado em 26 de setembro de 2005)

Uma das áreas de interesse na agricultura diz respeito ao controle biológico de pragas e doenças. Para isso, acredita-se que os fungos apresentam grande potencial, já que são vários os resultados promissores relatados na literatura para esses microrganismos (MELO
\& AZEVEDO, 2000). Em decorrência, buscou-se, em trabalho previamente realizado, isolar e identificar fungos para o controle de nematóides parasitas de plantas, o que permitiu obter 24 isolados fúngicos produtores de substâncias tóxicas a nematóides, segundo experimentos

\footnotetext{
1 Engenheiro Agrônomo, Rua Ramos Caiado, 457, Buriti - Alegre, GO - ufla-ddcc@bol.com.br

${ }^{2}$ Químico, D. Sc., Professor Adjunto, Departamento de Química da Universidade Federal de Lavras/UFLA - Cx. P. 3037 - $37200-000$ - Lavras, MG denilson@ufla.br

${ }^{3}$ Engenheiro Agrônomo, Ph.D., Professor Titular, Departamento de Fitopatologia/UFLA - Cx. P. 3037 - 37200-000 - Lavras, MG - nema@ufla.br

${ }^{4}$ Engenheiro Agrônomo, D.Sc., Professor Titular, Departamento de Agricultura /UFLA - Cx. P. 3037 - $37200-000$ - Lavras, MG - mpasqual@ufla.br

${ }^{5}$ Engenheiro Agrônomo, D. Sc., Professor Adjunto, Departamento de Agricultura/UFLA - Cx. P. 3037 - 37200-000 - Lavras, MG - renatomg@ufla.br

${ }^{6}$ Engenheiro Agrônomo, M. Sc., Departamento de Entomologia/UFLA - Cx. P. 3037-37200-000 - Lavras, MG - rogerioufla@yahoo.com.br
} 
realizados em laboratório (COSTA, 2000). Entretanto, no mesmo trabalho foi observado que um dos isolados mais promissores também produzia substâncias tóxicas às plantas cultiváveis em experimentos conduzidos em casade-vegetação, o que pode inviabilizar seu uso no controle de fitonematóides. Somando-se o referido resultado a relatos da literatura sobre a capacidade de produção de fitotoxinas por parte dos fungos Aspergillus spp. (STONARD \& MILLER-WIDEMAN, 1994), Fusarium spp. (ABBAS et al., 1995, 1998; SVABOVA \& LEBEDA, 2005; VESONDER et al., 2000), Paecilomyces vatiotii Bainer (NAKAJIMA et al., 1991), Penicillium spp. (STONARD \& MILLER-WIDEMAN, 1994), Sclerotinia sclerotiorum (Lib.) de Bary (PEDRAS \& AHIAHONU, 2004) e Verticillium spp. (BUCHNER et al., 1982; GUPTA et al., 1994; MEYER et al., 1994), que se encontravam entre os 24 fungos selecionados, tornou-se desejável ter à disposição uma metodologia rápida e simples para avaliar a fitotoxicidade dos metabólitos de origem fúngica. Com isso, seria possível eliminar mais facilmente os isolados fúngicos produtores de substâncias tóxicas à planta cultivada, sem a necessidade de montar e conduzir experimentos demorados e onerosos em casa-de-vegetação. Em decorrência do exposto trabalho objetivou-se avaliar a capacidade de produção de substâncias fitotóxicas por parte dos 24 fungos previamente selecionados, quando os mesmos eram cultivados nas condições previamente empregadas para a produção de metabólitos para o controle de nematóides (COSTA, 2000). Para alcançar tal objetivo, optou-se pelo teste in vitro com semente de alface (Lactuca sativa L. cv. Salad Bowl) e coleóptilo de trigo (Triticum aestivum L. cv. BRS-49), que têm sido utilizados na identificação de substâncias fitotóxicas de diversas fontes. Tais testes foram de grande importância, por exemplo, para a identificação das seguintes fitotoxinas de origem fúngica: chaetoglobosina $\mathrm{K}$, citreoviridina, cladosporina, ciclopenina, citocalasinas, diidropergilina, hidroxiterfenilina e da moniliformina (STONARD \& MILLER-WIDEMAN, 1994).

Os fungos Arthrobotrys conoides Drechsler (culturas 44-08 e 44-10), Arthrobotrys oligospora Fres., Arthrobotrys superba Corda, Aspergillus flavus Link: Fr., Coniothyrium sporulosum (W. Gams \& Domsch) van der Aa, Cunninghamella elegans Lendner, Cylindrocarpon magnusianum (Sacc.) Wollenw., Fusarium moniliforme Shelden (culturas 44-02 e 44-25), Fusarium oxysporum Schlecht (culturas 44-03 e 44-15), Fusarium solani (Mart.) Appel \& Wollenw. Emend. Snyd. \& Hans (culturas 44-01 e 44-18), Fusarium sp. (culturas 44-04 e 44-26), Monacrosporium doedycoides Drechsler, Mortierella sp.,
Paecilomyces lilacinus (Thom.) Samson, Paecilomyces variotii Bainer, Penicillium sp., Sclerotinia sclerotiorum (Lib.) de Bary, Trichoderma viride Pers. Ex Gray e Verticillium chlamydosporium Goddard, foram isolados por Costa (2000) e armazenados no Departamento de Fitopatologia da Universidade Federal de Lavras. Esses microrganismos foram cultivados em meio de cultura batatadextrose-agar durante dez dias, a $25^{\circ} \mathrm{C}$, sem incidência de luz. A seguir, discos com $5 \mathrm{~mm}$ de diâmetro de cada cultura foram adicionados a $200 \mathrm{~mL}$ de meio de cultura líquido Czapek-Dox $\left(0,5 \mathrm{~g} \mathrm{KCl}, 1 \mathrm{~g} \mathrm{KH}_{2} \mathrm{PO}_{4}, 2 \mathrm{~g} \mathrm{NaNO}_{3}, 30 \mathrm{~g}\right.$ sacarose, $0,01 \mathrm{~g} \mathrm{FeSO}_{4} .7 \mathrm{H}_{2} \mathrm{O}$ e $0,5 \mathrm{~g} \mathrm{MgSO}{ }_{4}$ em $1000 \mathrm{~mL}$ de água), conforme descrito por Costa (2000). Após 15 dias sob constante agitação, a $25^{\circ} \mathrm{C}$, no escuro, os micélios foram removidos por filtração em papel Whatman $\mathrm{N}^{\circ} 1$. Alíquotas de $80 \mathrm{~mL}$ de cada filtrado foram liofilizadas e cada um dos resíduos obtidos foi lavado com $14 \mathrm{~mL}$ de acetato de etila/ metanol (1:1). Concentraram-se os líquidos das lavagens sob vácuo, o que resultou em novos resíduos. Estes foram dissolvidos em $70 \mathrm{~mL}$ de água destilada para serem submetidos ao teste com alface. Para tanto, cinqüenta sementes desta planta foram dispostas em caixa de plástico transparente (GERBOX - 11,4 x 11,4 cm) contendo duas folhas de papel de germinação $(10,5 \times 10,5 \mathrm{~cm})$, embebidas com a solução a ser avaliada em quantidade igual a 2,5 vezes a sua massa. Depois de sete dias a $20^{\circ} \mathrm{C}$, sob fotoperíodo de 12 horas, as seguintes variáveis foram medidas: número de sementes não germinadas, plântulas sadias e com radículas necrosadas (BRASIL, 1992). Como controle negativo empregou-se o meio Czapek-Dox após liofilização e extração conforme descrito para os filtrados fúngicos. Os controles positivos foram soluções de glifosato a 17,14 mg/L e 8,85 $\mathrm{mg} / \mathrm{L}$, que foram preparadas pela dissolução em água de Agrisato $480 \mathrm{CS}$, produzido por Alkagro do Brasil Ltda. O experimento foi conduzido com quatro repetições (quatro GERBOX por tratamento), em delineamento inteiramente casualizado. Submeteram-se os resultados diretamente à análise de variância e as médias foram comparadas pelo teste de Scott \& Knott (1974), a 5\% de probabilidade.

Para o teste com trigo, $3 \mathrm{~mL}$ de cada filtrado fúngico foram liofilizados e lavados com $12 \mathrm{~mL}$ de acetato de etila/ metanol (1:1). Concentraram-se os líquidos das lavagens sob vácuo e solubilizaram-se os resíduos resultantes em 6 $\mathrm{mL}$ de solução aquosa de sacarose a $2 \%(\mathrm{~g} / \mathrm{mL})$, tamponada a pH 5,0 com $\mathrm{K}_{2} \mathrm{HPO}_{4}(1,794 \mathrm{~g} / \mathrm{mL})$ e ácido cítrico monoidratado $(1,019 \mathrm{~g} / \mathrm{mL})$ (NITSCH \& NITSCH, 1996), para serem submetidos à avaliação. As sementes de trigo foram dispostas em areia úmida e esterilizada, sem incidência de luz, durante três dias. Os primeiros $2 \mathrm{~mm}$ apicais de cinco 
plântulas estioladas foram descartados e os coleóptilos, que correspondiam aos próximos $4 \mathrm{~mm}$, foram colocados em 2 $\mathrm{mL}$ das soluções a serem avaliadas. Utilizou-se a solução tamponada de sacarose a $2 \%(\mathrm{~g} / \mathrm{mL})$ como controle negativo. Como controle positivo empregou-se solução de glifosato a 7,968 g/mL, que foi obtida conforme descrito acima. Após 20 horas a $25 \pm 2{ }^{\circ} \mathrm{C}$, no escuro, utilizou-se um paquímetro para medir os comprimentos dos coleóptilos que, a seguir, foram liofilizados e tiveram suas massas medidas em balança analítica. Empregaram-se três repetições (três tubos com cinco coleóptilos em cada um deles) em delineamento inteiramente casualizado. Os valores de comprimento para cada coleóptilo foram transformados em porcentagem, bem como os valores médios de massa dos coleóptilos de cada tubo, para serem submetidos à análise de variância. Os valores obtidos foram submetidos ao teste de Scott \& Knott (1974) a 5\% de probabilidade.

No teste com sementes de alface, dezenove filtrados fúngicos não diferiram estatisticamente da água e do meio czapek-dox. Apenas aqueles provenientes de $C$. magnusianum, F. moniliforme (cultura 44-02), Mortierella sp., $P$. lilacinus e Penicillium sp., foram tóxicos à alface, embora os valores obtidos tenham sido próximos aos observados para as testemunhas negativas (Tabela 1). Como $S$. sclerotiorum e espécies de Fusarium podem ser fitopatogênicos, efeitos pronunciados sobre alface eram esperados dos metabólitos de tais fungos. Especialmente para $F$. moniliforme e $F$. oxysporum, cujas habilidades para a produção de substâncias fitotóxicas são bem conhecidas (ABBAS et al., 1995, 1998; SVABOVA \& LEBEDA, 2005; VESONDER et al., 2000). No entanto, os efeitos dos metabólitos de tais fungos sobre a alface foram muito pequenos ou inexistentes, embora as sementes de tais plantas sejam consideradas altamente sensíveis a substâncias fitotóxicas (STONARD \& MILLERWIDEMAN, 1994) (Tabela 1). De forma análoga, nada foi observado para o filtrado de $P$. variotii, que pode produzir a fitotoxina cornexistina (NAKAJIMA et al., 1991).

Uma possível explicação para tais resultados pode residir na baixa capacidade do solvente acetato de etila para dissolver substâncias muito polares (HARBORNE, 1998; SHRINER et al., 1983). Ou seja, talvez alguns destes fungos tenham produzido substâncias fitotóxicas no meio de cultura czapek-dox que não tenham sido dissolvidas em acetato de etila/metanol (1:1). Para contornar este possível problema, acetato de etila foi totalmente substituído por metanol, que possui maior capacidade de solubilização de substâncias polares (HARBORNE, 1998; SHRINER et al., 1983). No entanto, tal procedimento mostrou-se inviável, uma vez que o extrato metanólico proveniente do meio Czapek-Dox, que era uma das testemunhas negativas, passou a afetar as sementes de alface. Como parece inviável um único sistema de solventes que permita extrair substâncias com as mais variadas polaridades (HARBORNE, 1998; SHRINER et al., 1983), acredita-se que será necessária a utilização de mais de um sistema de solventes para cobrir uma faixa ampla de polaridade. Ademais, outros meios de cultura terão de ser estudados para que se possa identificar aqueles cujos componentes não tenham efeitos fitotóxicos sobre alface.

Ao contrário do observado com alface, quase todos os filtrados fúngicos afetaram o crescimento de coleóptilo de trigo, sendo os resultados mais pronunciados observados para as amostras de A. conoides (cultura 4408) e $P$. variotii (Tabela 1). Apenas $F$. moniliforme (cultura 44-25) forneceu valores estatisticamente idênticos à solução aquosa de sacarose, que foi empregada como controle negativo. Considerando bem conhecido o potencial para o controle de agentes patogênicos, especialmente nematóides parasitas de plantas (SIDDIQUI \& MAHMOOD, 1996), foram surpreendentes os resultados observados para tais fungos e para A. oligospora, $M$. doedycoides, $T$. viride e $V$. chlamydosporium.

Talvez a grande diferença observada entre os resultados dos testes realizados se deva a maior sensibilidade do último a substâncias fitotóxicas. Outra possível explicação poderia basear-se no modo de absorção dos metabólitos fúngicos pelos materiais vegetais empregados. Assim como muitos herbicidas comerciais que são preferencialmente absorvidos pelas folhas (DEUBER, 1992), as substâncias fitotóxicas produzidas por tais fungos poderiam ser mais facilmente absorvidas pelos coleóptilos, que são precursores das folhas. Outra possível explicação para a referida diferença pode basear-se nas espécies vegetais empregadas. Ou seja, assim como os herbicidas sulfozato e glifosato, talvez os metabólitos dos fungos estudados apresentem maior fitotoxicidade a espécies monocotiledôneas (DEUBER, 1992; MACIEL et al., 2002; RODRIGUES \& ALMEIDA, 1998).

Estudos posteriores deverão ser realizados para averiguar a relação entre os resultados obtidos in vitro e os efeitos dos metabólitos fúngicos em casa-de-vegetação.

Segundo os testes de germinação de sementes de alface, quando cultivados em meio Czapek-Dox, os fungos $C$. magnusianum, F. moniliforme (cultura 44-02), Mortierella sp., P. lilacinus e Penicillium sp. produzem substâncias fitotóxicas. Já com base nos experimentos com coleóptilos de trigo, conclui-se que, com exceção de $F$. moniliforme (cultura 44-25), todos os fungos estudados produzem substâncias fitotóxicas quando cultivados no supracitado meio. 
TABELA 1 - Efeito de metabólitos fúngicos sobre a germinação de sementes de alface e sobre coleóptilos de trigo.

\begin{tabular}{|c|c|c|c|c|}
\hline \multirow[b]{2}{*}{ Fungos e testemunhas } & \multicolumn{2}{|c|}{ Alface* } & \multicolumn{2}{|c|}{ Coleóptilo de trigo* } \\
\hline & $\begin{array}{l}\text { Número de } \\
\text { Plântulas sadias }\end{array}$ & $\begin{array}{c}\text { Sementes não } \\
\text { germinadas }\end{array}$ & $\begin{array}{c}\text { Comprimento } \\
(\%)^{\square}\end{array}$ & $\begin{array}{c}\text { Ganho de massa } \\
(\%)^{\square}\end{array}$ \\
\hline Glifosato-1 $^{* *}$ & $0^{\mathrm{a}}$ & $2^{\mathrm{a}}$ & - & - \\
\hline Glifosato- $2^{* * *}$ & $45^{\mathrm{b}}$ & $2^{\mathrm{a}}$ & - & - \\
\hline Glifosato- $3 * * * *$ & - & - & $61^{\mathrm{a}}$ & $52^{\mathrm{b}}$ \\
\hline Água & $48,3^{\mathrm{c}}$ & $0,95^{\mathrm{a}}$ & - & - \\
\hline Sacarose a $2 \%$ & - & - & $100^{\mathrm{e}}$ & $100^{\mathrm{d}}$ \\
\hline Czapek-Dox ${ }^{\text {II }}$ & $47^{\mathrm{c}}$ & $1^{\mathrm{a}}$ & $96^{\mathrm{e}}$ & $95^{\mathrm{d}}$ \\
\hline Arthrobotrys conoides (44-08) & $48,8^{\mathrm{c}}$ & $0,75^{\mathrm{a}}$ & $65^{\mathrm{a}}$ & $41^{\mathrm{a}}$ \\
\hline A. conoides (44-10) & $49^{c}$ & $0,75^{\mathrm{a}}$ & $81^{\mathrm{d}}$ & $66^{\mathrm{c}}$ \\
\hline A. oligospora & $47^{\mathrm{c}}$ & $2^{\mathrm{a}}$ & $73^{\mathrm{b}}$ & $61^{\mathrm{b}}$ \\
\hline A. superba & $49^{c}$ & $0,25^{\mathrm{a}}$ & $83^{\mathrm{d}}$ & $72^{\mathrm{c}}$ \\
\hline Aspergillus flavus & $48^{\mathrm{c}}$ & $1,5^{\mathrm{a}}$ & $74^{\mathrm{b}}$ & $50^{\mathrm{b}}$ \\
\hline Coniothyrium sporulosum & $48,3^{\mathrm{c}}$ & $1,0^{\mathrm{a}}$ & $79^{\mathrm{c}}$ & $78^{\mathrm{c}}$ \\
\hline Cunninghamella elegans & $49,3^{\mathrm{c}}$ & $0,25^{\mathrm{a}}$ & $81^{\mathrm{d}}$ & $68^{\mathrm{c}}$ \\
\hline Cylindrocarpon magnusianum & $45^{\mathrm{b}}$ & $2,5^{\mathrm{a}}$ & $74^{\mathrm{b}}$ & $41^{\mathrm{a}}$ \\
\hline Fusarium moniliforme(44-02) & $44,8^{\mathrm{b}}$ & $2,5^{\mathrm{a}}$ & $67^{\mathrm{a}}$ & $49^{\mathrm{b}}$ \\
\hline F. moniliforme (44-25) & $49,8^{\mathrm{c}}$ & $0,25^{\mathrm{a}}$ & $96^{\mathrm{e}}$ & $95^{\mathrm{d}}$ \\
\hline F. oxysporum $(44-03)$ & $48^{\mathrm{c}}$ & $1,25^{\mathrm{a}}$ & $86^{\mathrm{d}}$ & $68^{\mathrm{c}}$ \\
\hline F. oxysporum (44-15) & $47,5^{\mathrm{c}}$ & $0,75^{\mathrm{a}}$ & $79^{\mathrm{c}}$ & $53^{\mathrm{b}}$ \\
\hline F. solani $(44-01)$ & $47^{\mathrm{c}}$ & $2^{\mathrm{a}}$ & $72^{\mathrm{b}}$ & $57^{\mathrm{b}}$ \\
\hline F. solani $(44-18)$ & $48,5^{\mathrm{c}}$ & $0,75^{\mathrm{a}}$ & $70^{\mathrm{b}}$ & $65^{\mathrm{c}}$ \\
\hline Fusarium sp. (44-04) & $48,5^{\mathrm{c}}$ & $0,75^{\mathrm{a}}$ & $88^{\mathrm{d}}$ & $82^{\mathrm{c}}$ \\
\hline Fusarium sp. (44-26) & $48,8^{\mathrm{c}}$ & $0,75^{\mathrm{a}}$ & $73^{\mathrm{b}}$ & $41^{\mathrm{a}}$ \\
\hline Monacrosporium doedycoides & $48,3^{\mathrm{c}}$ & $1,25^{\mathrm{a}}$ & $74^{\mathrm{b}}$ & $62^{\mathrm{b}}$ \\
\hline Mortierella sp. & $45^{\mathrm{b}}$ & $4,5^{\mathrm{b}}$ & $84^{\mathrm{d}}$ & $70^{\mathrm{c}}$ \\
\hline Paecilomyces. lilacinus & $42,5^{\mathrm{b}}$ & $5,75^{\mathrm{b}}$ & $84^{\mathrm{d}}$ & $67^{\mathrm{c}}$ \\
\hline P. variotii & $48,3^{\mathrm{c}}$ & $1,5^{\mathrm{a}}$ & $65^{\mathrm{a}}$ & $37^{\mathrm{a}}$ \\
\hline Penicillium sp. & $45^{\mathrm{b}}$ & $2,5^{\mathrm{a}}$ & $74^{\mathrm{b}}$ & $43^{\mathrm{a}}$ \\
\hline Sclerotinia sclerotiorum & $47,3^{\mathrm{c}}$ & $1,75^{\mathrm{a}}$ & $83^{\mathrm{d}}$ & $72^{\mathrm{c}}$ \\
\hline Trichoderma. viride & $48^{\mathrm{c}}$ & $1,25^{\mathrm{a}}$ & $75^{\mathrm{b}}$ & $60^{\mathrm{b}}$ \\
\hline Verticillium chlamydosporium & $47,3^{\mathrm{c}}$ & $1,0^{\mathrm{a}}$ & $78^{\mathrm{c}}$ & $66^{\mathrm{c}}$ \\
\hline Coeficiente de Variação & $4,76 \%$ & $10,4 \%$ & $8,23 \%$ & $12,04 \%$ \\
\hline
\end{tabular}

"Valores seguidos pela mesma letra, em cada coluna, não diferem estatisticamente segundo o teste de Scott-Knott a 5 $\%$ de probabilidade; $* * 17,14 \mathrm{mg} / \mathrm{l} ; * * * 8,85 \mathrm{mg} / \mathrm{l} ; * * * * 7,97 \mathrm{~g} / \mathrm{l} ;{ }^{\square}$ Valores relativos ao tratamento com sacarose a $2 \%$; "Após liofilização e extração; - Variáveis não avaliadas. 


\section{AGRADECIMENTO}

Os autores agradecem à Fundação de Amparo à Pesquisa do Estado de Minas Gerais (FAPEMIG), pela concessão de uma bolsa de iniciação científica.

\section{REFERÊNCIAS BIBLIOGRÁFICAS}

ABBAS, H. K.; BOYETTE, C. D.; HOAGLAND, R. E. Phytotoxicity of Fusarium, other fungal isolates, and of the phytotoxins fumonisin, fusaric acid, and moniliformin to jimsonweed. Phytoprotection, Chemin Sainte-Foy, v. 76, n. 1, p. 17-25, abr.1995.

ABBAS, H. K.; SHIER, W. T.; SEO, J. A.; LEE, Y. W.; MUSSER, S. M. Phytotoxicity and cytotoxicity of the fumonisin $\mathrm{C}$ and $\mathrm{P}$ series of mycotoxins from Fusarium spp. Fungi. Toxicon, London, v. 6, n. 12, p. 2033-2037, dez. 1998.

BRASIL. Ministério da Agricultura. Regras para análise de sementes. Brasília, DF, 1992.

BUCHNER, V.; NACHMIAS, A.; BURSTEIN, Y. Isolation and partial characterization of a phytotoxic glycopeptide from a protein-liposaccharide complex produced by a potato isolate of Verticillium dahliae. FEBS Lettters, Amsterdam, v. 138, n. 2, p. 261-264, fev. 1982.

COSTA, M. J. N. Filtrados de culturas fúngicas e extratos de plantas e de estercos animais, com ação antagonista a Meloidogyne incognita (Kofoid \& White) Chitwood. 2000. 115 p. Dissertação (Mestrado em Fitopatologia) Universidade Federal de Lavras, Lavras, 2000.

DEUBER, R. Ciência das plantas daninhas: fundamentos. Jaboticabal: FUNEP, 1992.

GUPTA, S.; PEISER, G.; NAKAJIMA, T.; HWANG, Y. S. Characterization of a phytotoxic cyclotetrapeptide, a novel chlamydocin analog, from Verticillium coccosporum. Tetrahedron Letters, Oxford, v. 35, n. 33, p. 6009-6012, ago. 1994.

HARBORNE, J. B. Phytochemical methods. London: Chapman \& Hall, 1998.

MACIEL, C. D. G; CONSTANTIN, J.; GOTO, R. Seletividade e eficiência agronômica de herbicidas no controle de capimcolchão na cultura da melancia. Horticultura Brasileira, Brasília, v. 20, n. 4, p. 474-476, dez. 2002.
MELO, I. S.; AZEVEDO, J. L. Controle biológico. Jaguariúna: Embrapa Meio Ambiente, 2000. v. 2.

MEYER, R.; SLATER, V.; DUBERY, I. A. A phytotoxic protein-liposaccharide complex produced by Verticillium dahliae. Phytochemistry, Oxford, v. 35, n. 6, p. 1449-1453, abr. 1994.

NAKAJIMA, M.; ITOI, K.; TAKAMATSU, Y.; SATO, S.; FURUKAWA, Y.; FURUYA, K.; HONMA, T.; KADOTANI, J.; KOZASA, M.; HANEISHI, T. Cornexistin: a new fungal metabolite with herbicidal activity. Journal of Antibiotics, Toquio, v. 44, n. 10, p. 1065-1072, Oct. 1991.

NITSCH, J. P.; NITSCH, C. Studies on the growth coleoptile and first internode sections: a new, sensitive, straightgrowth test for auxins. Plant Physiology, Rockville, v. 31, n. 2, p. 94-111, 1956.

PEDRAS, M. S. C.; AHIAHONU, P. W. K. Phytotoxin production and phytoalexin elicitation by the phytopathogenic fungus Sclerotinia sclerotiorum. Journal of Chemical Ecology, New York, v. 30, n. 11, p. 2163-2179, nov. 2004.

RODRIGUES, B. N.;ALMEIDA, F. S. Guia de herbicidas. Londrina: Ed. dos Autores, 1998.

SCOTT, A. J.; KNOTT, M. Cluster analysis method for grouping means in the analysis of variance. Biometrics, Washington, v. 30, n. 3, p. 507-512, 1974.

SHRINER, R. L.; FUSON, R. C.; CURTIN, D. Y.; MORRILL, T. C. Identificação sistemática dos compostos orgânicos. 6. ed. Portland: Book News, 1983.

SIDDIQUI, Z. A.; MAHMOOD, I. Biological control of plant parasitic nematodes by fungi: a review. Bioresource Technology, Oxford, v. 58, n. 3, p. 229-239, Dec. 1996.

STONARD, R. J.; MILLER-WIDEMAN, M. A. Herbicides and plant growth regulators. In: GODFREY, C. R. A. (Ed.) Agrochemicals from natural products. New York: M. Dekker, 1994. p. 215-255.

SVABOVA, L.; LEBEDA, A. In vitro selection for improved plant resistance to toxin-producing pathogens. Journal of Phytopathology, Berlin, v. 153, n. 1, p. 52-64, jan. 2005. 
VESONDER, R. F.; WU, W.; WEISLEDER, D.; GORDON, produce fumonisins, moniliformin and a new S. H.; KRICK, T.; XIE, W.; ABBAS, H. K.; MCALPIN, C. C21H38N2O6 metabolite phytotoxic to Lemna minor L. E.Toxigenic strains of Fusarium moniliforme and Journal of Natural Toxins, Fort Collins, v. 9, n. 2, p. 103Fusarium proliferatum isolated from dairy cattle feed 112, May 2000. 